\title{
Transition metal-modified polyoxometalates supported on carbon as catalyst in 2-(methylthio)-benzothiazole sulfoxidation
}

\author{
ROMINA A FRENZEL, GUSTAVO P ROMANELLI*, MIRTA N BLANCO and LUIS R PIZZIO* \\ Centro de Investigación y Desarrollo en Ciencias Aplicadas “Dr. Jorge J. Ronco” (CINDECA), \\ CCT-LaPlata-CONICET, Facultad de Ciencias Exactas, Universidad Nacional de La Plata, $47 \mathrm{~N}^{\circ} 257$ \\ (B1900AJK) La Plata, Argentina \\ e-mail: lppizzio@quimica.unlp.edu.ar; gpr@quimica.unlp.edu.ar
}

MS received 18 February 2014; revised 19 June 2014; accepted 22 June 2014

\begin{abstract}
Polyoxometalates with lacunary Keggin structure modified with transition metal ions $\left[\mathrm{PW}_{11} \mathrm{O}_{39}\right.$ $\left.\mathrm{M}\left(\mathrm{H}_{2} \mathrm{O}\right)\right]^{5-}$, where $\mathrm{M}=\mathrm{Ni}^{2+}, \mathrm{Co}^{2+}, \mathrm{Cu}^{2+}$ or $\mathrm{Zn}^{2+}$, were synthesized and supported on activated carbon to obtain the PW11MC catalysts. Using FT-IR and DTA-TGA it was concluded that the $\left[\mathrm{PW}_{11} \mathrm{O}_{39} \mathrm{M}\left(\mathrm{H}_{2} \mathrm{O}\right)\right]^{5-}$ species are interacting with the functional groups of the support, and that thermal treatment leads to the loss of the coordinatively bonded water molecules without any noticeable anion degradation. The activity and selectivity of the catalysts in the sulfoxidation reaction of 2-(methylthio)-benzothiazole, an emerging environmental pollutant, were evaluated. The reaction was carried out in acetonitrile as solvent using $\mathrm{H}_{2} \mathrm{O}_{2} 35 \% \mathrm{p} / \mathrm{v}$ as a clean oxidant. The conversion values decreased in the following order: PW11NiC $>$ PW $11 \mathrm{CuC}>\mathrm{PW} 11 \mathrm{CoC}$ $>$ PW11ZnC, with selectivity to sulfoxide higher than $69 \%$. The catalyst could be reused without appreciable loss of the catalytic activity at least three times. The materials were found to be efficient and recyclable catalysts for 2-(methylthio)-benzothiazole sulfoxidation in order to obtain a more biodegradable product than the corresponding substrate.
\end{abstract}

Keywords. Supported metal-substituted polyoxometalates; carbon; sulfoxidation; 2-(methylthio)benzothiazole oxidation; hydrogen peroxide.

\section{Introduction}

The oxidation reaction of organic substrates is one of the most important transformations in organic chemistry, and its products are used in the production of bulk and fine chemicals such as perfumes, pharmaceuticals and organic intermediates. ${ }^{1}$ Traditional methods for this transformation are the use of stoichiometric oxidants such as $\mathrm{K}_{2} \mathrm{Cr}_{2} \mathrm{O}_{7}$ or $\mathrm{KMnO}_{4}$, which produce large amounts of unwanted toxic waste. ${ }^{2}$ From both economic and environmental viewpoints, molecular oxygen and aqueous hydrogen peroxide as green oxidants have received intensive attention because they are inexpensive and water is produced as the only by-product.

In the last two decades, inorganic solid-catalyzed organic transformations are gaining much importance due to the proven advantage of heterogeneous catalysts, such as simplified product isolation, mild reaction conditions, high selectivity, easy recovery and catalyst reuse, and reduction in the generation of waste by-products. $^{3-5}$

Catalysis by heteropolyacids (HPA) and related compounds (HPC) is a field of increasing importance

*For correspondence worldwide. Numerous developments are being carried out in basic research as well as in fine chemistry processes. ${ }^{6}$ The reactions catalyzed by both heterogeneous and homogeneous systems have been reviewed by many researchers. ${ }^{7-13}$ Our research group has applied Keggin heteropolyacids in diverse clean processes. ${ }^{14-20}$

Particularly, transition metal-modified lacunary heteropoly compounds of the general formula $\left[\mathrm{XW}_{11} \mathrm{O}_{39}\right.$ $\mathrm{M}]^{\mathrm{n}-}$, where $\mathrm{X}=\mathrm{P}$ or $\mathrm{Si}$ and $\mathrm{M}=$ first row transition metal, have recently attracted considerable attention..$^{21,22}$ This is because of their thermal and chemical stability and the range of possibilities for their modification without affecting the Keggin-type primary structure. ${ }^{23}$ The robust nature of the polyoxometalate ligand and its resistance to oxidation are advantages that allow the use of these species in both polar and non-polar solvents ${ }^{24}$ as homogeneous catalysts. ${ }^{25}$

Transition metal-modified lacunary heteropoly compounds with Keggin structure, obtained by modification of the $\left[\mathrm{PW}_{11} \mathrm{O}_{39}\right]^{7-}$ lacunary phase with ions of the transition metals Ni (II), Fe (III), Co (II), Zn (II), Mn (II) or $\mathrm{Cu}$ (II), have been used as catalysts in the oxidation of cyclohexane with aqueous $\mathrm{H}_{2} \mathrm{O}_{2}{ }^{26}$ and methyl isobutyrate and cyclohexene with oxygen. ${ }^{27,28}$ The above reactions carried out in homogeneous liquid phase have 
the disadvantage that the recovery of the catalyst from the reaction mixture for reuse is difficult.

Advantages to be highlighted about using supported transition metal-modified lacunary heteropoly compounds as catalysts are their easiness of recovery and recycling after carrying out liquid phase reactions, when they are compared to the homogeneously catalyzed reactions. Activated carbon has been found to efficiently entrap Keggin heteropolyacids. ${ }^{29}$ The compounds thus entrapped are hardly removed even by extraction with water.

On the other hand, sulfoxides and sulfones are important intermediates in organic chemistry due to their application in fundamental research and other extended usage. ${ }^{30}$ The most widely used method for the preparation of sulfoxides and sulfones is the oxidation of the corresponding sulfide. ${ }^{30-34}$

In the last decade, very useful procedures involving catalysis and hydrogen peroxide as oxidant have been developed. They promote the oxidation of organic substrates primarily due to the environment-friendly character of hydrogen peroxide. These obvious advantages have encouraged the development of useful procedures for hydrogen peroxide oxidation of sulfides, including the use of a wide range of catalysts based on metal or semimetals, for example heteropolyacids. ${ }^{18,35}$

Benzothiazoles (BT) are used in a variety of industrial products and processes and are manufactured worldwide. ${ }^{36}$ These compounds are used as herbicides, algicides, fungicides, photosensitizers and in the rubber industry. ${ }^{37}$

Due to their widespread application, persistence and toxicity, benzothiazole derivatives have remained an environmental concern. Benzothiazoles have been detected in atmospheric aerosols, surface water, street dust, street runoff, sediment, starry flounder liver and an industrial effluent from a tyre manufacturer. ${ }^{38}$ Additionally, benzothiazoles have been found to cause eye, skin and respiratory irritation. A previous study of in vivo and in vitro effects of BT on sheepshead minnow indicated that benzothiazoles were a gill toxicant and not a neurotoxicant and another study also suggested 2-methylthiobenzothiazole (2-MTBT) shows acute aquatic toxicity in various test systems. ${ }^{38,39}$

The selective oxidation of 2-MTBT to the corresponding sulfoxide is very useful, since the product formed has a biodegradability higher than the starting material under consideration. ${ }^{40}$
The aim of this paper is to study the use of carbonsupported transition metal-modified lacunary heteropoly compounds as new catalytic materials in the sulfoxidation of 2-MTBT to the corresponding sulfoxide, a more biodegradable product than the corresponding substrate with aqueous hydrogen peroxide (scheme 1).

\section{Experimental}

\subsection{Catalyst synthesis}

2.1a Transition metal-modified lacunary heteropolycompound synthesis: The lacunary heteropoly compounds modified with transition metal ions $\left[\mathrm{PW}_{11} \mathrm{O}_{39}\right.$ $\mathrm{M}]^{5-}, \mathrm{M}=\mathrm{Ni}^{2+}, \mathrm{Co}^{2+}, \mathrm{Cu}^{2+}$, or $\mathrm{Zn}^{2+}$, were prepared according to the literature data. ${ }^{41-43}$ Their synthesis involves the alkalization of an aqueous solution of $\mathrm{H}_{3} \mathrm{PW}_{12} \mathrm{O}_{40} \cdot 23 \mathrm{H}_{2} \mathrm{O}$ with aqueous $\mathrm{NaHCO}_{3}$ solution up to a $\mathrm{pH}$ value of 5.0-5.5, which results in the formation of the lacunary heteropolyanion $\left[\mathrm{PW}_{11} \mathrm{O}_{39}\right]^{7-}$. In order to introduce the transition metal ion into the octahedral lacuna, the obtained solution of $\left[\mathrm{PW}_{11} \mathrm{O}_{39}\right]^{7-}$ and an aqueous solution of the transition metal salt were mixed and stirred at $60-90^{\circ} \mathrm{C}$. The sodium salts of the lacunary heteropoly compounds were obtained by solvent evaporation and recrystallization from water. They were dried at $70^{\circ} \mathrm{C}$ before their characterization by thermal and physicochemical techniques.

2.1b Supported catalyst synthesis: The catalysts based on transition metal-modified polyoxometalates supported on carbon were obtained using the incipient wetness method. The support used was commercial activated carbon ground to a mean particle size of $1 \mathrm{~mm}$, previously washed with $0.1 \mathrm{~N}$ solutions of $\mathrm{NaOH}$ and $\mathrm{HCl}$, and then treated with a $\mathrm{HNO}_{3} 30 \%$ solution under heating to reflux for $2 \mathrm{~h}$. It has a surface area of $806 \mathrm{~m}^{2} / \mathrm{g}$ and a mean pore diameter below $2 \mathrm{~nm}$. The carbon was impregnated using the incipient wetness method, with $\left[\mathrm{PW}_{11} \mathrm{O}_{39} \mathrm{M}\right]^{5-}$ water solutions $(0.14 \mathrm{M})$, in order to add $1.010^{-4} \mathrm{~mol}$ of the lacunary heteropoly compounds per gram of carbon. The catalysts were kept at room temperature till dryness and then thermally treated at $70^{\circ} \mathrm{C}$ for $24 \mathrm{~h}$. The catalysts are named as PW $11 \mathrm{MC}$. For comparison, a catalyst based on the lacunary heteropolyanion $\left[\mathrm{PW}_{11} \mathrm{O}_{39}\right]^{7-}(\mathrm{PW} 11 \mathrm{C})$ was synthesized using the same procedure.

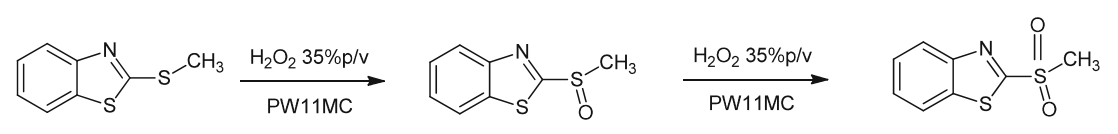

Scheme 1. Proposed oxidation of 2-MTBT. 
A fraction of the solid thus obtained was washed with acetonitrile, chloroform or toluene for two $24 \mathrm{~h}$ periods. For this leaching experiment, $1 \mathrm{~g}$ of solid was placed in contact with $4 \mathrm{~mL}$ of solvent at $20^{\circ} \mathrm{C}$ under constant stirring for a selected time.

The tungsten concentration in the solutions, after leaching, was determined by atomic absorption spectrometry. The calibration curve method was used, with standards prepared in the laboratory. An IL Model 457 spectrophotometer, with single channel and double beam and monochromator with a $330 \mathrm{~mm}$ focal distance, was used. The light source was a hollow monocathode lamp. The analysis was carried out at wavelength $254.9 \mathrm{~nm}$, bandwidth $0.3 \mathrm{~nm}$, lamp current $15 \mathrm{~mA}$, phototube amplification $800 \mathrm{~V}$, burner height $4 \mathrm{~mm}$ and acetylene-nitrous oxide flame (11:14).

\subsection{Catalyst characterization}

Fourier transform infrared spectroscopy (FT-IR) spectra of $\left[\mathrm{PW}_{11} \mathrm{O}_{39} \mathrm{M}\right]^{5-}$ sodium salts and catalysts dried at $70^{\circ} \mathrm{C}$ for $24 \mathrm{~h}$ were obtained in the $400-4000 \mathrm{~cm}^{-1}$ wavenumber range using Bruker IFS 66 FT-IR spectrometer.

$\mathrm{X}$-ray diffraction (XRD) patterns were recorded on the same samples that had been analyzed by FT-IR. The equipment used to this end was Philips PW-1732 with built-in recorder, using $\mathrm{Cu} \mathrm{K} \alpha$ radiation, nickel filter, $30 \mathrm{~mA}$ and $40 \mathrm{kV}$ in the high voltage source, and scanning angle between 5 and $60^{\circ}$ of $2 \theta$ at a scanning rate of $1^{\circ}$ per minute.

The distribution of $\left[\mathrm{PW}_{11} \mathrm{O}_{39} \mathrm{M}\right]^{5-}$ anions along the width of the carbon granules was measured with a Philips Model 505 scanning electron microscope with an energy dispersive X-ray analysis (EDAX) system, following a technique previously reported. ${ }^{44,45}$

Thermogravimetric and differential thermal analyses (TG-DTA) of the solids were carried out using a Shimadzu DT 50 thermal analyzer, under argon or nitrogen respectively, using $25-50 \mathrm{mg}$ samples and a heating rate of $10^{\circ} \mathrm{C} / \mathrm{min}$. The studied temperature range was $20-700^{\circ} \mathrm{C}$.

Temperature-programmed reduction (TPR) data of the samples dried at $70^{\circ} \mathrm{C}(100 \mathrm{mg}, 60$ to $100 \mathrm{mesh})$ were obtained using a mixture of $\mathrm{H}_{2}(5 \%)$ in Ar flowing at $90 \mathrm{~mL} / \mathrm{min}$. The heating rate was kept at $10^{\circ} \mathrm{C} / \mathrm{min}$ until reaching a temperature of $1000^{\circ} \mathrm{C}$. The amount of $\mathrm{H}_{2}$ consumed during the reduction was determined using a thermal conductivity detector.

\subsection{Catalytic tests}

The oxidation of 2-(methylthio)-benzothiazole to the corresponding sulfoxide or sulfone (scheme 1) was carried out in a reactor batch at atmospheric pressure by stirring a solution of $1 \mathrm{mmol}$ of the substrate and $100 \mathrm{mg}$ of the catalyst in $9 \mathrm{~mL}$ of acetonitrile, which was immersed in an oil bath with temperature control at the required temperatures $\left(20-60^{\circ} \mathrm{C}\right)$. The oxidant used was $\mathrm{H}_{2} \mathrm{O}_{2} 35 \%$ (w/v) in aqueous solution $(0.1-1 \mathrm{~mL})$. Aliquots were withdrawn from the reaction mixture during the reaction at different time intervals. GC/MS analyses were performed on HP 5971 mass detector coupled to HP gas chromatograph fitted with a $30 \mathrm{~m} \times$ $0.5 \mathrm{~mm}$ DB5 capillary column. The percentages of each compound in the reaction mixture were directly estimated from the corresponding chromatographic peak areas.

The conversion was calculated as mol $\%$ of consumed substrate and the selectivity as mol\% of the product to mol of substrate. Blank experiments without catalyst and using only the support were performed.

After reaction, the catalyst was filtered, washed thoroughly with acetonitrile $(2 \times 3 \mathrm{~mL})$, dried under vacuum, and reused in the oxidation reaction, following the procedure described above.

\subsection{Product identification}

2.4a Mass spectra of 2-(methylthio)-benzothiazole sulfoxide: $\mathrm{m} / \mathrm{z}(\mathrm{I} \%) 197$ (62) $\mathrm{M}^{+.} ; 182$ (78); 153 (60); 151 (100); 150 (64); 134 (42\%); 123 (15); 108 (25); 90 (26); 50 (30); 39 (98).

2.4b Mass spectra of 2-(methylthio)-benzothiazole sulfone: $\mathrm{m} / \mathrm{z}(\mathrm{I} \%): 197$ (18) $\mathrm{M}^{+}$; 150 (100); 134 (42); 108 (20); 90 (25); 50 (24); 39 (74).

2.4c Mass spectra of 2-hydroxybenzothiazole: $\mathrm{m} / \mathrm{z}$ (I \%): 151 (100) $\mathrm{M}^{+.} ; 123$ (55); 96 (57); 45 (60); 39 (50).

\section{Results and Discussion}

The $\left[\mathrm{PW}_{11} \mathrm{O}_{39} \mathrm{M}\right]^{5-}$ anions are attached on the activated carbon surface as a result of the electrostatic type interaction among them and the carbon different functional groups present on the support surface. ${ }^{46}$ The treatment with nitric acid makes the carbon more acidic ${ }^{47}$ and as per results, groups such as hydroxyl, diol or ether, together with other less basic groups can be protonated. However, the adsorption might not be purely electrostatic, involving in addition, covalent interactions in variable degree, as in the interaction between soft cations and anions. ${ }^{48}$ 


\subsection{Catalyst characterization}

The infrared spectra of $\mathrm{Na}_{5}\left[\mathrm{PW}_{11} \mathrm{O}_{39} \mathrm{M}\right]$, with $\mathrm{M}=$ $\mathrm{Ni}^{2+}, \mathrm{Co}^{2+}, \mathrm{Cu}^{2+}$, or $\mathrm{Zn}^{2+}$ (figure 1), show absorption bands characteristic of the transition metal-modified lacunary heteropoly compounds in the range of 700$1100 \mathrm{~cm}^{-1}$. $^{49}$ The spectrum of the $\left[\mathrm{PW}_{12} \mathrm{O}_{40}\right]^{3-}$ anion shows a prominent band at $1080 \mathrm{~cm}^{-1}$ assigned to the v3 vibration of the central $\mathrm{PO}_{4}$ tetrahedron. In the $\left[\mathrm{PW}_{11} \mathrm{O}_{39}\right]^{7-}$ anion spectrum, this band is split into two components $\left(1085-1040 \mathrm{~cm}^{-1}\right)$, due to the symmetry decrease of the $\mathrm{PO}_{4}$ tetrahedron.

For the $\left[\mathrm{PW}_{11} \mathrm{O}_{39} \mathrm{M}\right]^{5-}$ anions, the value of the $v 3$ PO4 splitting, $\Delta v$, is always lower than that of the free ligand $\left[\mathrm{PW}_{11} \mathrm{O}_{39}\right]^{7-}$ anion. The filling of the hole in the octahedral lacuna by the $\mathrm{M}$ cation to some extent restores the symmetry of the central tetrahedron, owing to the interaction between $\mathrm{M}$ and the available oxygen of the central $\mathrm{PO}_{4}$ group (Oa). The $\Delta v$ values observed for the $\mathrm{Na}_{5}\left[\mathrm{PW}_{11} \mathrm{O}_{39} \mathrm{M}\right]$ compounds (table 1) are in close agreement with those reported for the potassium salts of similar $\left[\mathrm{PW}_{11} \mathrm{O}_{39} \mathrm{M}\right]^{5-}$ anions. ${ }^{49}$ The variation

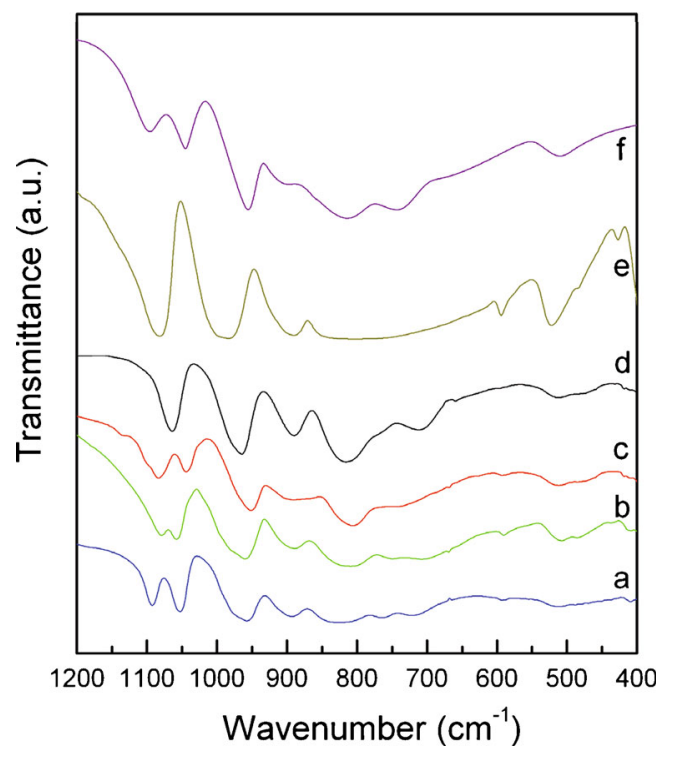

Figure 1. (a) FT-IR spectra of the transition metalmodified lacunary Keggin heteropoly compounds $\left[\mathrm{PW}_{11} \mathrm{O}_{39} \mathrm{M}\right]^{5-}$, with $\mathrm{M}=\mathrm{Zn}^{2+}$; (b) $\mathrm{Co}^{2+}$; (c) $\mathrm{Cu}^{2}$; (d) $\mathrm{Ni}^{2+}$; (e) $\mathrm{H}_{3} \mathrm{PW}_{12} \mathrm{O}_{40}$ and (f) $\mathrm{Na}_{7} \mathrm{PW}_{11} \mathrm{O}_{39}$. of $\Delta v$ with respect to the $\mathrm{M}$ electronic configuration is similar to that of the ligand-field stabilization energy of transition metals, complexed by weak-field ligands in an octahedral surrounding. ${ }^{49}$ This correlation is consistent with the fact that the $\left[\mathrm{PW}_{11} \mathrm{O}_{39}\right]^{7-}$ polyanion is a weak-field ligand. The $\Delta v$ values provide an indirect measure of the interaction strength of the metal $\mathrm{M}$ with the $\mathrm{Oa}$ atom, being higher for lower $\Delta v$. The comparison of the obtained values shows that the interaction strength decreases in the following order: $\mathrm{Ni}^{2+}>\mathrm{Co}^{2+}>\mathrm{Zn}^{2+}>\mathrm{Cu}^{2+}$. The particularly large $\Delta v$ value displayed for the $\left[\mathrm{PW}_{11} \mathrm{O}_{39} \mathrm{Cu}\right]^{5-}$ anion is assigned to the distortion of the $\mathrm{CuO}_{6}$ octahedron (Jahn-Teller effect) involving a rather long $\mathrm{Cu}-\mathrm{Oa}$ distance with respect to $\mathrm{Cu}-\mathrm{Ob}$ and $\mathrm{Cu}-\mathrm{Oc}$ distances and consequently, a rather weak $\mathrm{Cu}-\mathrm{Oa}$ interaction. ${ }^{49}$ These results, which are in agreement with those previously reported, confirm that the $\mathrm{M}$ cation was incorporated into the framework of the $\left[\mathrm{PW}_{11} \mathrm{O}_{39}\right]^{7-}$ polyanion.

The FT-IR spectra of the PW11NiC, PW11CoC, PW11CuC, and PW11ZnC samples show the characteristic bands of the $\left[\mathrm{PW}_{11} \mathrm{O}_{39} \mathrm{M}\right]^{5-}\left(\left[\mathrm{PW}_{11} \mathrm{O}_{39} \mathrm{Ni}\right]^{5-}\right.$, $\left[\mathrm{PW}_{11} \mathrm{O}_{39} \mathrm{Co}\right]^{5-},\left[\mathrm{PW}_{11} \mathrm{O}_{39} \mathrm{Cu}\right]^{5-}$, or $\left[\mathrm{PW}_{11} \mathrm{O}_{39} \mathrm{Zn}\right]^{5-}$ anions, respectively) superimposed to those of the support. These results confirm that the structure of the metal-modified lacunary heteropoly compounds remains unaltered after the interaction with carbon that takes place during the impregnation.

XRD patterns of PW11MC samples were similar to those of the original carbon. They present neither the diffraction lines of the $\mathrm{Na}_{5}\left[\mathrm{PW}_{11} \mathrm{O}_{39} \mathrm{M}\right]$ salts, nor those of other crystalline phases. On the other hand, in previous work ${ }^{21}$ we reported, according to the results obtained by energy dispersive X-ray analysis (EDAX), a uniform distribution of the modified lacunary Keggin anions along the width of the carbon. Based on these results, we concluded that the species present onto the support surface are highly dispersed as a non-crystalline form, owing to the interaction with the support.

The thermal decomposition of sodium $\left[\mathrm{PW}_{11} \mathrm{O}_{39} \mathrm{M}\right]^{5-}$ takes place at temperatures higher than $470^{\circ} \mathrm{C}$ (table 1). According to the DTA studies, $\mathrm{Na}_{5}\left[\mathrm{PW}_{11} \mathrm{O}_{39} \mathrm{Ni}\right]$ and $\mathrm{Na}_{5}\left[\mathrm{PW}_{11} \mathrm{O}_{39} \mathrm{Zn}\right]$ salts are thermally more stable than

Table 1. FT-IR and DTA results of the metal-modified lacunary heteropoly compounds.

\begin{tabular}{lccccc}
\hline Catalyst & $\begin{array}{c}\Delta v \\
\left(\mathrm{~cm}^{-1}\right)\end{array}$ & $\begin{array}{c}\text { Dehydration } \\
\text { Temperature }\left({ }^{\circ} \mathrm{C}\right)\end{array}$ & $\begin{array}{c}\text { Decomposition } \\
\text { temperature }\left({ }^{\circ} \mathrm{C}\right)\end{array}$ & $\operatorname{TPR}_{\mathrm{MAX}}\left({ }^{\circ} \mathrm{C}\right)$ \\
\hline $\mathrm{Na}_{5}\left[\mathrm{PW}_{11} \mathrm{O}_{39} \mathrm{Co}\right]$ & 18 & 54 & 497 & 642 & 858 \\
$\mathrm{Na}_{5}\left[\mathrm{PW}_{11} \mathrm{O}_{39} \mathrm{Ni}\right]$ & 0 & $82-136$ & 509 & 643 & 892 \\
$\mathrm{Na}_{5}\left[\mathrm{PW}_{11} \mathrm{O}_{39} \mathrm{Cu}\right]$ & 41 & 65 & 480 & 666 & 960 \\
$\mathrm{Na}_{5}\left[\mathrm{PW}_{11} \mathrm{O}_{39} \mathrm{Zn}\right]$ & 37 & $48-74$ & 506 & 693 & 970 \\
\hline
\end{tabular}


the $\mathrm{Na}_{5}\left[\mathrm{PW}_{11} \mathrm{O}_{39} \mathrm{Cu}\right]$ and $\mathrm{Na}_{5}\left[\mathrm{PW}_{11} \mathrm{O}_{39} \mathrm{Co}\right]$ ones. The dehydration of the salts occurs at temperatures below $150^{\circ} \mathrm{C}$. TG diagrams show a continuous weight loss, which was reflected in the DTA diagram as the appearance of one broad peak or a couple of unresolved endothermic peaks (table 1).

The DTA diagrams of the PW11NiC, PW11CoC, $\mathrm{PW} 11 \mathrm{CuC}$, and $\mathrm{PW}_{11} \mathrm{ZnC}$ samples show an endothermic peak with maximum at around $70^{\circ} \mathrm{C}$ ascribed to water evolution, which is similar to that displayed by the support. A wide exothermic signal assigned to metal-modified lacunary Keggin anion decomposition with maximum in the range $500-520^{\circ} \mathrm{C}$ was observed. The decomposition temperature of the modified lacunary Keggin anion is slightly enhanced by the interaction with the functional groups present on the support surface. ${ }^{46}$

The same conclusion was drawn from the DTA diagrams of $\mathrm{PW} 11 \mathrm{CoC}, \mathrm{PW} 11 \mathrm{CuC}$ and $\mathrm{PW} 11 \mathrm{ZnC}$ samples, which display the maximum of the wide exothermic peak assigned to the decomposition at 510, 505 and $515^{\circ} \mathrm{C}$, respectively.

The TPR patterns of $\mathrm{Na}_{5}\left[\mathrm{PW}_{11} \mathrm{O}_{39} \mathrm{M}\right]$ salts show two peaks (table 1) with maximum at temperatures higher than the decomposition temperature of the $\left[\mathrm{PW}_{11} \mathrm{O}_{39} \mathrm{M}\right]^{5-}$ anion and are assigned to the reduction of the species resulting from anion decomposition. These species may be the constituent oxides of the decomposed salts. Gamelas et al..$^{50}$ have found $\mathrm{WO}_{3}$ as the main component of the decomposition products of potassium salts of transition metal-modified lacunary heteropoly compounds. The reduction temperature increases according to the following order: $\mathrm{Na}_{5}\left[\mathrm{PW}_{11}\right.$ $\left.\mathrm{O}_{39} \mathrm{Ni}\right]<\mathrm{Na}_{5}\left[\mathrm{PW}_{11} \mathrm{O}_{39} \mathrm{Cu}\right]<\mathrm{Na}_{5}\left[\mathrm{PW}_{11} \mathrm{O}_{39} \mathrm{Co}\right]<\mathrm{Na}_{5}$ $\left[\mathrm{PW}_{11} \mathrm{O}_{39} \mathrm{Zn}\right]$. The same peaks, shifted to lower temperatures, are present in the patterns of $\mathrm{Na}_{7}\left[\mathrm{PW}_{11} \mathrm{O}_{39}\right]$ (639 and $\left.861^{\circ} \mathrm{C}\right) .^{21}$

The TPR pattern of PW11MC samples (figure 2) presents a strong peak with a maximum in the range $580-610^{\circ} \mathrm{C}$, overlapping the band of the support. As a result of the interaction of the $\left[\mathrm{PW}_{11} \mathrm{O}_{39} \mathrm{M}\right]^{5-}$ anion with the functional groups present on the activated carbon surface, the reduction of decomposition products takes place at lower temperatures than those of bulk $\mathrm{Na}_{5} \mathrm{PW}_{11} \mathrm{O}_{39} \mathrm{M}$. The reduction temperature of these samples (TPR PW11MC $\left._{1}\right)$ increases according to the following order: $\mathrm{PW} 11 \mathrm{NiC}\left(584^{\circ} \mathrm{C}\right)<\mathrm{PW} 11 \mathrm{CuC}\left(587^{\circ} \mathrm{C}\right)<$ $\mathrm{PW} 11 \mathrm{CoC}\left(602^{\circ} \mathrm{C}\right)<\mathrm{PW} 11 \mathrm{ZnC}\left(606^{\circ} \mathrm{C}\right)$.
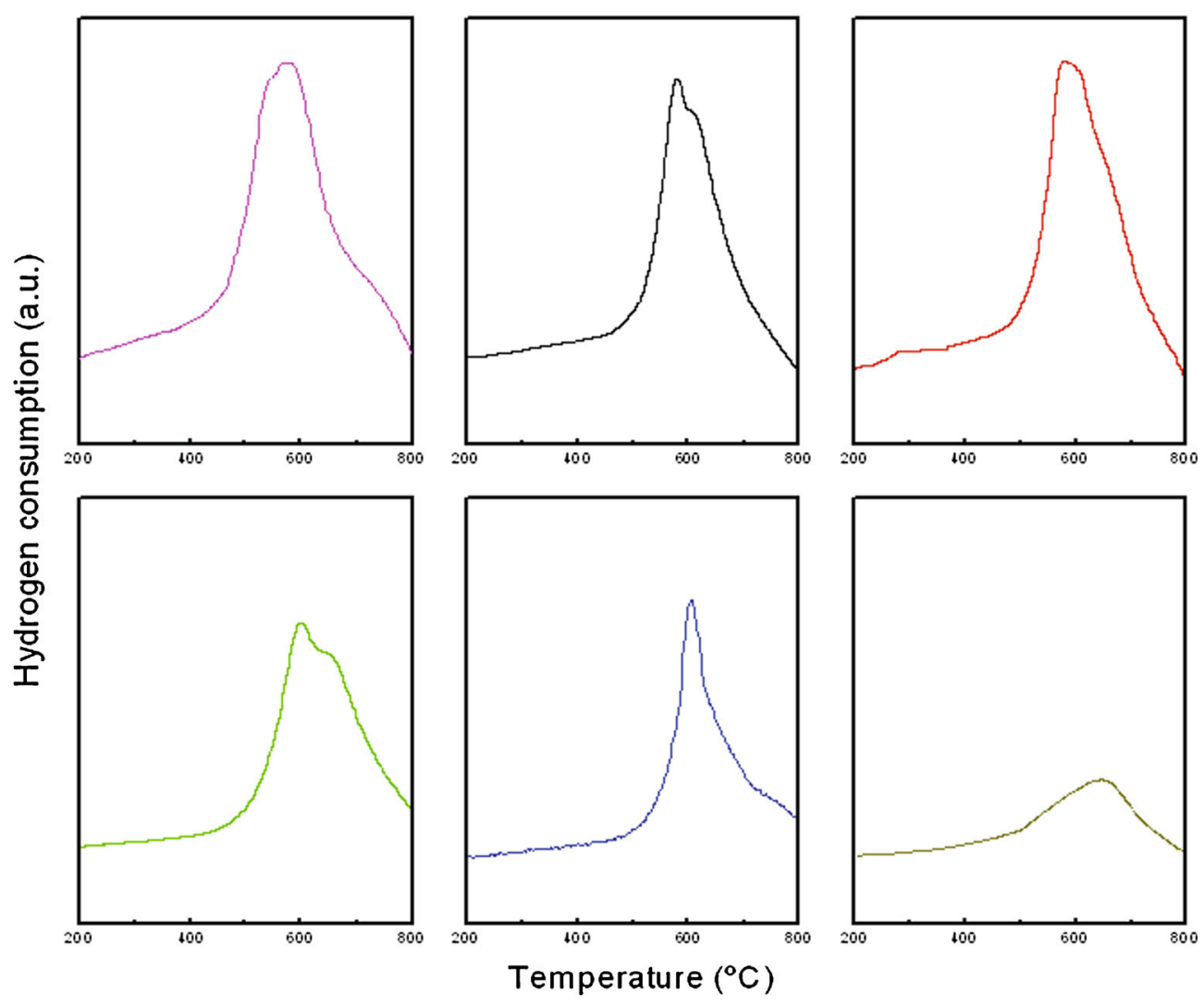

Figure 2. (a) TPR patterns of the samples PW11C; (b) PW11NiC; (c) PW11CuC; (d) PW11 CoC; (e), PW11ZnC; (e) and of the carbon support. 


\subsection{Catalytic activity}

This work describes the application of a heterogeneous system (using acetonitrile as solvent) for the oxidation of sulfides, particularly 2-(methylthio)-benzothiazole (2-MTBT), to the corresponding sulfoxide or sulfone with aqueous hydrogen peroxide in the presence of transition metal-modified polyoxometalates supported on carbon (PW11MC) as catalyst. The influence of dopant metal atom in the primary structure of the different synthesized catalysts was also considered.

The blank experiment was performed in the absence of the catalyst using an excess of aqueous $\mathrm{H}_{2} \mathrm{O}_{2}(35 \%$ $(\mathrm{w} / \mathrm{v}), 1 \mathrm{~mL})$. Under these conditions, the reaction conversion was low $\left(20 \%\right.$ at $300 \mathrm{~min}$ and $\left.40^{\circ} \mathrm{C}\right)$. Similarly, the support without PW11M was used as catalyst. Under similar reaction conditions, the conversion was almost the same (28\%).

Table 2 lists the results for 2-MTBT conversion and selectivity to the corresponding sulfoxide and sulfone using the different catalysts considered. The experimental conditions were: $100 \mathrm{mg}$ of catalyst, $1 \mathrm{mmol}$ of 2-MTBT, $1 \mathrm{~mL}$ of $\mathrm{H}_{2} \mathrm{O}_{2}(35 \%(\mathrm{w} / \mathrm{v}))$ and $9 \mathrm{~mL}$ of acetonitrile; reaction time and temperature of $300 \mathrm{~min}$ and $40^{\circ} \mathrm{C}$, respectively. In these conditions, sulfoxide and sulfone were obtained with a high selectivity (98-99\%) and only traces of a secondary product, 2-hydroxybenzothiazole, were obtained.

\section{2a Effect of the nature of the transition metal on} the catalytic activity of PW11MC samples: The prepared polyoxometalates with lacunary Keggin structure modified with transition metal ions supported on carbon (PW11NiC, PW11CoC, PW11CuC and PW11ZnC) and the PW11C sample were used as catalysts in 2MTBT oxidation. The results are listed in table 2. The PW11NiC catalyst showed an excellent conversion of $100 \%$ in $300 \mathrm{~min}$ (table 2, entry 1) and the conversion values decreased in the following order: $\mathrm{PW} 11 \mathrm{NiC}>$ PW11CuC $>$ PW11CoC $>$ PW11ZnC (table 2, entries 1-4). Additionally, the selectivity of the catalysts was a little sensitive to the type of cation used in the modification of the lacunary phase $(69 \%, 70 \%, 72 \%$ and $74 \%$, respectively). On the other hand, regardless of the cation incorporated into the framework of the $\left[\mathrm{PW}_{11} \mathrm{O}_{39}\right]^{7-}$ polyanion, the PW11MC samples showed higher catalytic activity than PW11C (table 2, entry 5). So, the use of lacunary Keggin structure modified with transition metal instead of $\left[\mathrm{PW}_{11} \mathrm{O}_{39}\right]^{7-}$ allowed us to increase the catalytic activity of the synthetized materials.

The previously mentioned order was opposite to that found for the TPR $\mathrm{PW}_{\mathrm{P} 1 \mathrm{MC}}$ values. In other words, the activity of the catalysts decreases in parallel with the increment of the $\mathrm{TPR}_{\mathrm{PW} 1 \mathrm{MC}}$ values. So, easier the reduction of the catalyst, higher is the conversion value.

It has been suggested ${ }^{51}$ that the oxidation of diphenyl sulfide catalyzed by Mo-based Keggin heteropolyacids takes place through the formation of peroxo-molybdate species and the subsequent nucleophilic attack of the sulfur atom in the sulfide to the peroxo species.

Additionally, it is known that thioethers are oxidized to sulfoxides by electrophilic oxidants. Mechanistically, it is believed that the electrophilicity of the peroxide oxygen of $\mathrm{H}_{2} \mathrm{O}_{2}$ is increased by an oxometal group $(\mathrm{M}=\mathrm{Od})$ in the heteropolycompound. ${ }^{52}$

We can suggest that the higher conversion values obtained using the more easily reducible $\left[\mathrm{PW}_{11}\right.$ $\left.\mathrm{O}_{39} \mathrm{M}\right]^{5-}$ anion could be due to a higher increase in electrophilicity of the peroxide oxygen of $\mathrm{H}_{2} \mathrm{O}_{2}$ by their oxometal groups.

The possible mechanism for the oxidation of 2(methylthio)-benzothiazole to the corresponding sulfoxide or sulfone using $\mathrm{H}_{2} \mathrm{O}_{2}$ in the presence of heteropoly compounds is outlined in scheme $2 \mathrm{a}$ and $2 \mathrm{~b}$. The interaction of hydrogen peroxide with HPC generates an electrophilic intermediate (peroxo oxygen/metal), which produces an electrophilic attack to the sulfur atom in the sulfide generating the corresponding sulfoxide (scheme $2 a$ ).

The mechanism for the oxidation of the sulfoxide to the corresponding sulfone is different. First it invol-

Table 2. Conversion and selectivity of the PW11MC samples in 2-MTBT oxidation.

\begin{tabular}{lccc}
\hline Catalyst & Conversion $(\%)$ & $\begin{array}{c}\text { Sulfoxide } \\
\text { selectivity (\%) }\end{array}$ & $\begin{array}{c}\text { Sulfone } \\
\text { selectivity (\%) }\end{array}$ \\
\hline PW11NiC & 100 & 69 & 30 \\
PW11CuC & 90 & 70 & 29 \\
PW11CoC & 80 & 72 & 26 \\
PW11ZnC & 75 & 74 & 24 \\
PW11C & 52 & 68 & 24 \\
\hline
\end{tabular}

Experimental conditions: $100 \mathrm{mg}$ catalyst, $1 \mathrm{mmol}$ of 2-(methylthio)-benzothiazole, $1 \mathrm{ml}$ of $\mathrm{H}_{2} \mathrm{O}_{2}(35 \% \mathrm{w} / \mathrm{v})$ and $9 \mathrm{ml}$ of acetonitrile; reaction for $300 \mathrm{~min}$ at $40^{\circ} \mathrm{C}$. 
a) 2-(methylthio)-benzothiazole oxidation to the corresponding sulfoxide

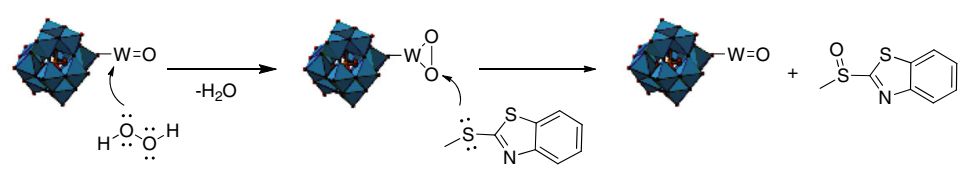

b) 2-(methylthio)-benzothiazole sulfoxide oxidation to the corresponding sulfone

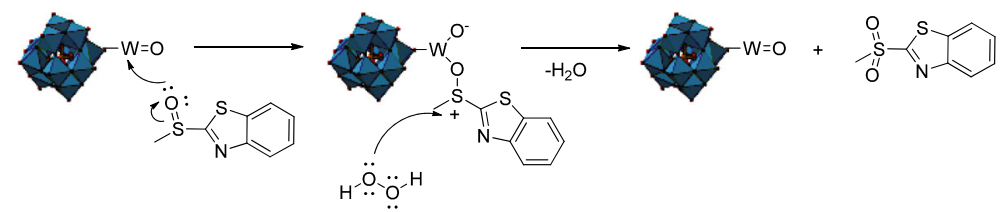

Scheme 2. Proposed mechanism for the oxidation of 2-(methylthio)-benzothiazole to the corresponding sulfoxide and sulfone with aqueous hydrogen peroxide in the presence of polyoxometalates.

ves the formation of an HPC-sulfoxide intermediate through the nucleophilic attack to the tungsten atom in the HPC by the oxygen of the sulfoxide, and then the nucleophilic attack of the sulfur atom in HPC-sulfoxide by $\mathrm{H}_{2} \mathrm{O}_{2}$ via a SN2 mechanism ${ }^{52-54}$ (scheme $2 b$ ).

On the other hand, Ishii et al. ${ }^{55}$ reported the influence of the acidity rate on the formation of peroxo complexes. Furthermore, Shaabani and Rezayan ${ }^{56}$ showed that the selective oxidation of sulfides to sulfoxides or sulfones in the presence of aqueous $\mathrm{H}_{2} \mathrm{O}_{2}$ was promoted by Brønsted acidity. We have found ${ }^{21}$ that the Brønsted acidity of the catalysts decreases in the following way: PW11NiC > PW11CuC $>$ PW11CoC $>$ PW11ZnC. Taking into account our results and previous reports ${ }^{55,56}$ we suggest that both the ease of reduction and the acidity strongly affect the catalytic activity of the PW11MC samples.

\section{$3.2 \mathrm{~b}$ Effect of the reaction conditions on the catalytic} oxidation of 2-MTBT: The influence of the reaction temperature on the reactivity of 2-MTBT oxidation was investigated using the more active catalyst, PW11NiC, and the results are illustrated in figure 3 . In order to obtain the optimal temperature, four temperatures $(20$, 30,40 and $60^{\circ} \mathrm{C}$ ) were tested.

The experimental reaction conditions were: $100 \mathrm{mg}$ of catalyst, $1 \mathrm{mmol}$ of 2-MTBT, $1 \mathrm{~mL}$ of $\mathrm{H}_{2} \mathrm{O}_{2}(35 \%$ $\mathrm{w} / \mathrm{v}$ ) and $9 \mathrm{~mL}$ of acetonitrile; the reaction time tested was in the range between 30 and $420 \mathrm{~min}$.

A very low conversion was observed at $20^{\circ} \mathrm{C}$ and a temperature increase led to a higher 2-MTBT conversion. The value for a reaction time of $90 \mathrm{~min}$ at $20^{\circ} \mathrm{C}$ was only $10 \%$, whereas at $60^{\circ} \mathrm{C}$ the conversion was $100 \%$, which is 10 times higher than that at $20^{\circ} \mathrm{C}$. However, the sulfoxide selectivity decreased from 80 to $40 \%$. This diminution is due to the further oxidation

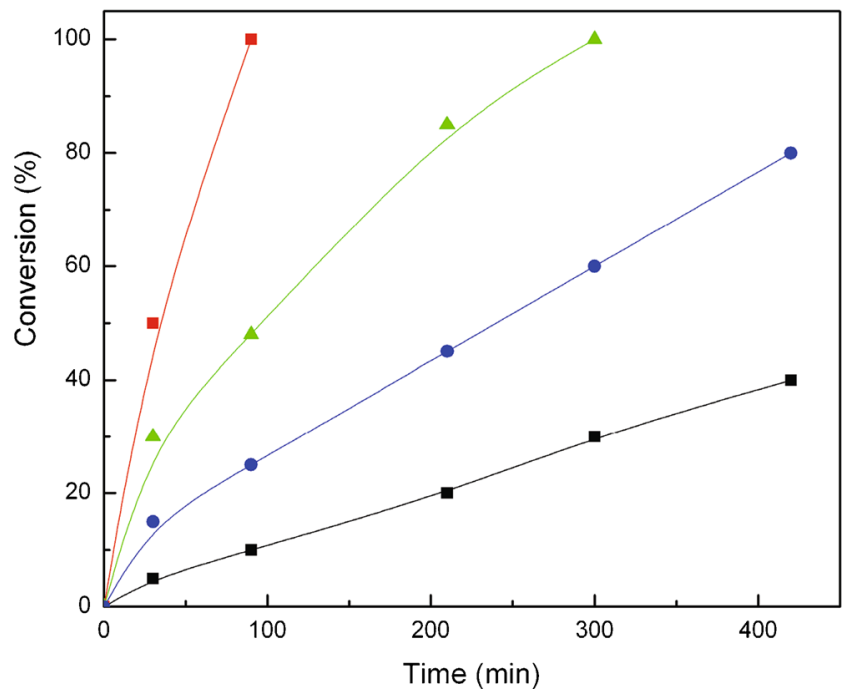

Figure 3. Conversion of 2-(methylthio)-benzothiazole sulfoxidation at a reaction temperature of $20(\square), 30(\bullet), 40(\Delta)$ and $60(\bar{\nabla})^{\circ} \mathrm{C}$ employing PW11 NiC as catalyst.

Table 3. Effect of the amount of the PW11NiC catalyst on the conversion of 2-MTBT and the selectivity to the sulfoxide.

\begin{tabular}{lcc}
\hline Amount $(\mathrm{mg})$ & $\begin{array}{c}\text { Time for a } \\
\text { conversion of } 100 \%\end{array}$ & $\begin{array}{c}\text { Sulfoxide } \\
\text { selectivity (\%) }\end{array}$ \\
\hline 25 & 1500 & 80 \\
50 & 600 & 80 \\
100 & 300 & 75 \\
150 & 240 & 66 \\
\hline
\end{tabular}

Experimental conditions: $1 \mathrm{mmol}$ of 2-(methylthio)-benzothiazole, $1 \mathrm{~mL}$ of $\mathrm{H}_{2} \mathrm{O}_{2}(35 \% \mathrm{w} / \mathrm{v})$ and $9 \mathrm{~mL}$ of acetonitrile; reaction for $300 \mathrm{~min}$ at $40^{\circ} \mathrm{C}$.

of 2-(methylthio)-benzothiazole sulfoxide to 2-(methylthio)-benzothiazole sulfone with the hydrogen peroxide excess. 
A similar behaviour in conversion and selectivity was found by studying the effect of increasing the amount of oxidant and catalyst used in the reaction.

Experimental conditions: $1 \mathrm{mmol}$ of 2-(methylthio)benzothiazole, $1 \mathrm{~mL}$ of $\mathrm{H}_{2} \mathrm{O}_{2}(35 \% \mathrm{w} / \mathrm{v})$ and $9 \mathrm{~mL}$ of acetonitrile; reaction for $300 \mathrm{~min}$ at $40^{\circ} \mathrm{C}$.

Table 3 displays the effect of the amount of the PW11NiC catalyst on the conversion of 2-MTBT and the selectivity to the corresponding sulfoxide in the reaction. It shows the reaction time for a $100 \%$ conversion of substrate and the corresponding sulfoxide selectivity. It can be observed that the time for a $100 \%$ conversion of 2-MTBT decreased from 1500 to $240 \mathrm{~min}$ when the amount of PW11NiC increased from 25 to $150 \mathrm{mg}$. At the same time, the sulfoxide selectivity decreased from 88 to $66 \%$ though it remained constant when the catalyst amount increased from 25 to $50 \mathrm{mg}$.

Figure 4 shows the influence of the amount of $35 \%$ w/v hydrogen peroxide on the conversion of 2-MTBT and the selectivity of the corresponding sulfoxide using PW11NiC as catalyst. The substrate conversion was positively dependent on the amount of hydrogen peroxide and reached a maximum value of 100 when $1 \mathrm{~mL}$ of $35 \% \mathrm{H}_{2} \mathrm{O}_{2}$ was used. An important decrease in the conversion of 2-MTBT was observed with the decrease in the amount of hydrogen peroxide. For example, the conversion of 2-MTBT was only $30 \%$ while using $0.1 \mathrm{~mL}$ of hydrogen peroxide. The theoretical molar ratio of hydrogen peroxide to 2-MTBT for the sulfoxide synthesis is $1: 1$. However, the results suggest that an excess of hydrogen peroxide is needed for

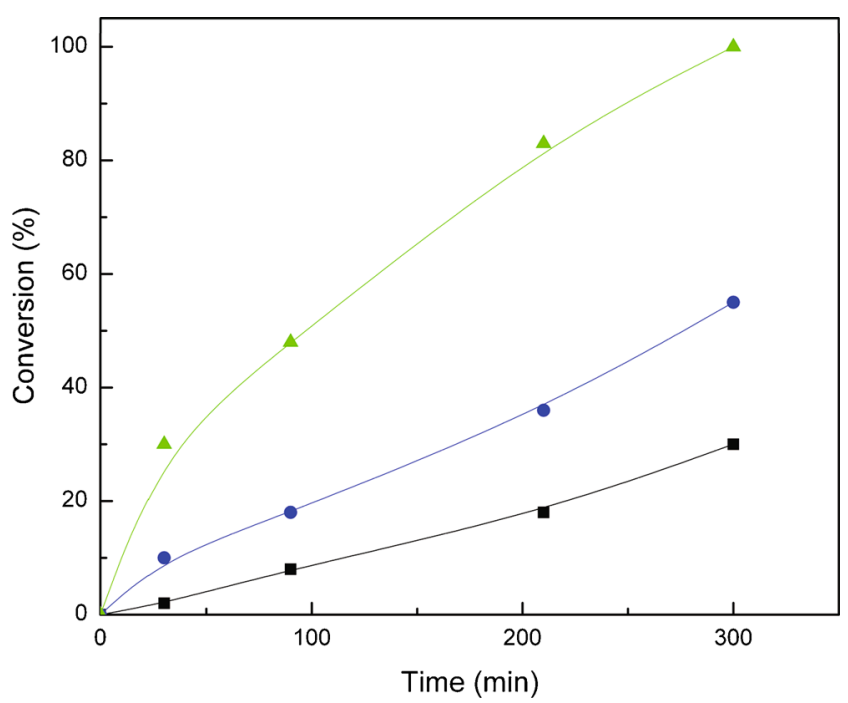

Figure 4. Effect of the amount $0.1(\square), 0.5(\bullet)$, and $1.0 \mathrm{~mL}$ ( $\triangle$ ) of $\mathrm{H}_{2} \mathrm{O}_{2}(35 \% \mathrm{w} / \mathrm{v})$ on the conversion of 2-MTBT using PW11NiC as catalyst. Experimental conditions: $1 \mathrm{mmol}$ of 2(methylthio)-benzothiazole, $100 \mathrm{mg}$ of catalyst and $9 \mathrm{~mL}$ of acetonitrile; reaction for $300 \mathrm{~min}$ at $40^{\circ} \mathrm{C}$. improving 2-MTBT conversion, as a consequence of hydrogen peroxide decomposition.

3.2c Catalyst reuse and leaching test: The use of the supported catalysts allows an easy separation and recovery of the catalyst for its immediate reutilization. It is recovered by filtration, washing with acetonitrile and drying. The recycled catalyst was subjected to a second or even a third reaction. In the model reaction, the results of the first experiment and the subsequent ones were consistent in conversion (a value of $100 \%$ was obtained in $300 \mathrm{~min}$ at $40^{\circ} \mathrm{C}$ using PW11 NiC as catalyst for the first, and the second and the third cycles). The sulfoxide selectivity for the three consecutive batches was the same (75\%). So, the activity of the so-treated catalyst was the same as that of the fresh catalyst. Thus it is noteworthy to mention that the catalyst is recyclable and could be reused without significant loss of activity.

In order to evaluate the possible catalyst solubilization, an additional test was performed. The PW11NiC sample was refluxed in acetonitrile for $300 \mathrm{~min}$, filtered and dried in vacuum till constant weight. The refluxed acetonitrile was used as solvent for attempting the reaction without adding the catalyst. After 300 min under reaction, 2-MTBT conversion was $20 \%$, the same value as that of the blank experiment without catalyst.

Finally, in order to explore a possible reaction mechanism, an additional experiment was performed using $t$-butanol as radical inhibitor. The experimental conditions were: $100 \mathrm{mg}$ of catalyst, $1 \mathrm{mmol}$ of 2(methylthio)-benzothiazole, $1 \mathrm{~mL}$ of $\mathrm{H}_{2} \mathrm{O}_{2}(35 \% \mathrm{w} / \mathrm{v})$, $100 \mathrm{mg}$ of PW11NiC, $8 \mathrm{~mL}$ of acetonitrile and $1 \mathrm{~mL}$ of $t$-butanol; reaction for $300 \mathrm{~min}$ at $40^{\circ} \mathrm{C}$. In these conditions, a similar conversion of 2-MTBT (100\%) and selectivity of sulfoxide (75\%) were obtained, compared to the initial experiment without the radical inhibitor. This result demonstrates that the reaction mechanism is not via a free radical oxidation.

\section{Conclusions}

The synthesis of the sodium salts of the transition metal-modified lacunary heteropolyanions leads to compounds with a slightly lower thermal stability than that of the parent lacunary $\mathrm{Na}_{7} \mathrm{PW}_{11} \mathrm{O}_{39}$. Their reduction temperature is slightly higher and increases according to the following order: $\mathrm{Na}_{5}\left[\mathrm{PW}_{11} \mathrm{O}_{39} \mathrm{Ni}\right]$ $<\mathrm{Na}_{5}\left[\mathrm{PW}_{11} \mathrm{O}_{39} \mathrm{Cu}\right]<\mathrm{Na}_{5}\left[\mathrm{PW}_{11} \mathrm{O}_{39} \mathrm{Co}\right]<\mathrm{Na}_{5}\left[\mathrm{PW}_{11}\right.$ $\left.\mathrm{O}_{39} \mathrm{Zn}\right]$. The $\left[\mathrm{PW}_{11} \mathrm{O}_{39} \mathrm{M}\right]^{5-}$ anion is the main species present in PW11MC materials. As a result of the interaction with the support surface groups, their decomposition temperature was only slightly affected. 
The activity of the synthesized catalysts in the reaction of 2-MTBT sulfoxidation decreased in the following order: PW11NiC $>$ PW11CuC $>$ PW11CoC $>$ PW11ZnC, yielding selectivity to sulfoxide higher than $69 \%$, at a reaction temperature of $40^{\circ} \mathrm{C}$ and $300 \mathrm{~min}$ of reaction time. The ease of reduction and the acidity affect the catalytic activity of the PW11MC samples.

When carbon-supported modified heteropolyoxometalates are used as catalysts, the heterogeneous liquid phase sulfoxidation of 2-MTBT takes place without significant loss to the active phase, facilitating separation and reuse. The use of aqueous hydrogen peroxide gives only water as a by-product and thus contributing to the field of clean technologies.

Finally, the conversion of 2-MTBT in the corresponding sulfoxide is an environmentally important procedure, due to its limited biodegradability and potential toxicity.

\section{Acknowledgements}

The authors thank Agencia Nacional de Promoción Científica y Tecnológica, CONICET and Universidad Nacional de La Plata (Argentina) for the financial support and L. Osiglio, D. Peña and N. Firpo for their collaboration in the experimental measurements.

\section{References}

1. Wang L, Li J, Zhao X, Lva Y, Zhanga H and Gao S 2013 Tetrahedron 696041

2. Hudlicky M 1990 In Oxidations in Organic Chemistry (Washington DC: American Chemical Society)

3. Clark J H 2002 Acc. Chem. Res. 35791

4. Okuhara T 2002 Chem. Rev. 1023641

5. Gorsd M, Pizzio L and Blanco M 2011 Appl. Catal. A: Gen. 40091

6. Misono M and Nojiri N 1990 Appl. Catal. A: Gen. 641

7. Okuhara T 2002 Catal. Today 73167

8. Mizuno N and Misono M 1998 Chem. Rev. 98199

9. Kozhevnikov I V 1998 Chem. Rev. 98171

10. Yadav G 2005 Catal. Surveys from Asia 9117

11. Méndez L, Torviso R, Pizzio L and Blanco M 2011 Catal. Today 17332

12. Misono M, Ono I, Koyano G and Aoshima A 2000 Pure Appl. Chem. 721305

13. Pizzio L R, Vázquez P G, Cáceres C V and Blanco M N 2003 Appl. Catal. A: Gen. 256125

14. Bennardi D, Romanelli G, Autino J, Pizzio L, Vázquez P, Cáceres C and Blanco M 2010 React. Kinet. Mechanism Catal. 100165

15. Romanelli G, Autino J, Vázquez P, Pizzio L, Blanco M and Cáceres C 2009 Appl. Catal. A: Gen. 352208

16. Romanelli G P, Autino J C, Blanco M N and Pizzio L R 2005 Appl. Catal. A: Gen. 295209

17. Pizzio L, Romanelli G, Vázquez P, Autino J, Blanco M and Cáceres C 2006 Appl. Catal. A: Gen. 308153
18. Tundo P, Romanelli G, Vázquez P and Aricó F 2010 Catal. Commun. 111181

19. Tundo P, Romanelli G, Vázquez P, Loris P and Aricó F 2008 Synlett 967

20. Villabrille P, Romanelli G, Vázquez $\mathrm{P}$ and Cáceres $\mathrm{C}$ 2008 Appl. Catal. A: Gen. 334374

21. Pizzio L R and Blanco M N 2007 Mater. Lett. 61719

22. Izumi Y, Urabe K and Onaka A 1992 In Zeolite, Clay and Heteropolyacid in Organic Reactions, Kodansha (Tokyo-VCH: Weinheim)

23. Pope M T 1983 In Heteropoly and Isopoly Oxometalates (Berlin: Springer)

24. Katsoulis D E and Pope M T 1984 J. Am. Chem. Soc. 1062737

25. Kozhevnikov I V 1995 Catal. Rev. Sci. Eng. 37 (2) 311

26. Simoes M M Q, Conceiao C M M, Gamelas J A F, Domínguez P M D N, Cavaleiro A M V, Cavaleiro J A S, Ferrer-Correira A J V and Johnstone R A W 1999 J. Mol. Catal. A.: Chem. 144461

27. Ellis S and Kozhevnikov I V 2002 J. Mol. Catal. A: Chem. 187227

28. Hu J and Burns R C 2002 J. Mol. Catal. A: Chem. 184 451

29. Chimienti M E, Pizzio L R, Cáceres C V and Blanco M N 2001 Appl. Catal. A: Gen. 2087

30. Liu F, Fu Z, Liu Y, Lu Ch, Wu Y, Xie F, Ye Z, Zhon X and Yin D 2010 Ind. Eng. Chem. Res. 492533

31. Varma R, Sain R and Meshram H 1997 Tetrahedron Lett. 386525

32. Tajbakhsh M, Hosseinzadeh R and Shakoori A 2004 Tetrahedron Lett. 451889

33. Lakouraj M, Tajbakhsh M, Shirini F, Tamami M A 2005 Synth. Commun. 35775

34. Shukla V, Salgaonkar P and Akamanchi K 2003 J. Org. Chem. 685422

35. Romanelli G, Bennardi D, Palermo V, Vázquez $\mathrm{P}$ and Tundo P 2007 Lett. Org. Chem. 4544

36. Bunescu A, Besse-Hoggan P, Sancelme M, Mailhot G, Delort A M 2008 Appl. Environ. Microbiol. 742976

37. Asimakopoulos A G, Ajibola A, Kannan K and Thomaidis N S 2013 Sci. Total Environ 452163

38. Gangni H, Huilu F, Linluo X, Yutian H and Zeng A 2008 China. Environ Sci. Technol. 421892

39. Reemtsma T, Fiehn O, Kalnowski G and Jekel M 1995 Environ. Sci. Technol. 29478

40. Kinen C O, Rossi L I and Rossi R H de 2006 Appl. Catal A: Gen 312120

41. Weakley T J R and Malik S A 1967 J. Inorg. Nucl. Chem. 292935

42. Tourné C M, Tourné G F, Malik S A and Weakley T J R 1970 J. Inorg. Nucl. Chem. 323875

43. Zonnevijlle F, Tourné C M and Tourné G F 1982 J. Inorg. Chem. 212751

44. Pizzio L R, Vázquez P G, Cáceres C V and Blanco M N 1996 Adsorpt. Sci. Technol. 13165

45. Viturro H, Bonetto R, Pizzio L R, Vázquez P G, Sánchez $\mathrm{M}$ and Alvarez G 1995 X-Ray Spectrom. 243

46. Abotsi G K M and Scaroni A W 1990 Carbon 2879

47. Schwegler M A, Vinke P, Eijk M van der and Bekkum $\mathrm{H}$ van 1992 Appl. Catal. A: Gen. 8041

48. Pizzio L R, Cáceres C V and Blanco M N 1997 J. Colloid Interface Sci. 190318 
49. Rocchiccioli-Deltcheff $\mathrm{C}$ and Thouvernot R $1977 \mathrm{~J}$. Chem. Res. (S) 46549

50. Gamelas J A, Couto F A S, Trovão M C N, Cavaleiro A M V, Cavaleiro J A S and DeJesus J D P 1999 Thermochim. Acta $\mathbf{3 2 6} 165$

51. Palermo V, Romanelli G P and Vazquez P G $2013 \mathrm{~J}$. Mol. Catal. A: Chem. 373142

52. Maciuca A L, Ciocan C E, Dumitriu E, Fajula F and Hulea V 2008 Catal. Today 13833
53. Chellamani A and Harikengaram S 2006 J. Mol. Catal. A: Chem. 247 (1-2) 260

54. Smith J R L, Gilbert B C, Payeras, J Murray A Mairata i, Lowdon T R, Oakes J, Prats R Pons i and P H Walton 2006 J. Mol. Catal. A: Chem. 251114

55. Ishii Y, Yamawaki K, Ura, Yamada H, Yoshida $\mathrm{T}$ and Ogawa M 1998 J. Org. Chem. 533581

56. Shaabani A and Rezayan A H 2007 Catal. Commun. 8 1112 